2016-08-01

\title{
Creep analysis of concrete with different mineral admixtures
}

$\mathrm{He}, \mathrm{Z}$

http://hdl.handle.net/10026.1/17859

10.1166/mex.2016.1319

Materials Express

American Scientific Publishers

All content in PEARL is protected by copyright law. Author manuscripts are made available in accordance with publisher policies. Please cite only the published version using the details provided on the item record or document. In the absence of an open licence (e.g. Creative Commons), permissions for further reuse of content should be sought from the publisher or author. 


\title{
Creep analysis of concrete with different mineral admixtures
}

\author{
Zhihai $\mathrm{He}^{1,2,3}$, Chunxiang Qian², Longyuan $\mathrm{Li}^{3}$, and Shigui $\mathrm{Du}^{1, *}$ \\ ${ }^{1}$ College of Civil Engineering, Shaoxing University, Shaoxing 312000, China \\ ${ }^{2}$ College of Materials Science and Engineering, Southeast University, Nanjing 211189, China \\ ${ }^{3}$ School of Marine Science and Engineering, University of Plymouth, PL4 8AA, UK
}

\begin{abstract}
In order to comprehensively master the effect of different mineral admixtures on the creep behavior of concrete, the mechanical properties and creep of concrete with active mineral admixtures (i.e., fly ash (FA), ground granulated blast-furnace slag (GGBS), metakaolin (MK)) and inert mineral admixtures (i.e., limestone powder (LP), quartz sand powder (QSP) and emery powder (EP)) were studied by using a self-made testing device. The corresponding effect mechanism was also analyzed according to the internal relative humidity (IRH) and pore microstructure organization of the mixed concrete. The results show that the use of FA and/or GGBS can reduce the creep of concrete, and more creep can be reduced if both MK and inert mineral admixtures are used, although different mineral admixtures have different effects on the compressive strength and elastic modulus of the mixed concrete. The correlation between specific creep and IRH can be characterized in three different zones. The combined use of FA and GGBS can reduce the pore volume of pores of different sizes, and the concrete mixes with MK and inert mineral admixtures have very similar pore size distribution to provide more resistance to their creep.
\end{abstract}

Keywords: Creep, Concrete, Mineral Admixture, Compressive Strength, Elastic Modulus.

\section{INTRODUCTION}

Creep is defined as the increase in strain under a sustained constant stress, which is the inherent time-varying characteristic of concrete material. The creep strain is composed of two main parts. One is the basic creep, and the other is the drying creep which is due to concrete drying. ${ }^{(1-3)}$ In general, the creep strain depends largely on the drying creep. In practical engineering, the sum of the basic and drying creep strains is considered for the design of concrete structures. Creep of concrete is one important part of concrete volume stability, which affects directly the safety of concrete structures. ${ }^{(4)}$ Creep has both positive and negative effects on the performance of concrete structures. On the positive side, for example, creep can reduce the

*Author to whom correspondence should be addressed.

Email: dsg@usx.edu.cn stress concentrations caused by the temperature variation and shrinkage. ${ }^{(5)}$ On the negative side, for example, creep can cause the continuous increase of pre-stress loss, the long term deformation and the internal stress redistribution of concrete structures, especially for large span prestressed concrete bridges. ${ }^{(6,7)}$ The negative side of creep is mainly considered in the design and construction of concrete structures. In general, a stable, less creep value is desirable for concrete structures to be built.

In recent years, a growing number of studies show that concrete creep is mainly related with the hydration products especially for calcium silicate hydrate $(\mathrm{C}-\mathrm{S}-\mathrm{H})$ generated by cementitious materials including cement and different mineral admixtures. ${ }^{\left({ }^{(-10)}\right.}$ Mineral admixtures such as fly ash (FA), ground granulated blast-furnace slag (GGBS) and metakaolin (MK) not only can improve the engineering properties of mixed concrete, but also reduce 
the cement content used in the mix and thus make concrete more sustainable for they can reduce both construction costs and material-related $\mathrm{CO}_{2}$ emissions. ${ }^{(11-13)}$ Therefore, there has been an increasing interest in the use of mineral admixtures in modern concrete, which is an indispensable component in producing high performance concrete. The active mineral admixtures can react with calcium hydroxide generated by cement hydration to produce additional $\mathrm{C}-\mathrm{S}-\mathrm{H}$, which has the most important effect on creep of concrete. There are many studies on creep of concrete with various different mineral admixtures. Khatri et al. ${ }^{(14)}$ and Siddique $^{(15)}$ investigated the effect of mineral admixtures on creep of concrete at a constant water-binder ratio of 0.35. It was found that the creep of concrete with low content of GGBS by weight of binder was low when compared to that of concrete without mineral admixtures, and silica fume added to concrete in amount of $10 \%$ by weight of binder decreased the creep of concrete remarkably. The combination of silica fume in amount of $10 \%$ by weight of binder and FA also decreased the creep of mixed concrete. However, the creep of mixed concrete was found to be higher than that of concrete with a single silica fume. FA alone in amount of $15 \% \sim 25 \%$ by weight of binder had little effect on concrete creep. Mazloom et al. ${ }^{(15,16)}$ reported that, with the increase of silica fume content in the mixture the creep of concrete was lower, and when the content of silica fume was up to $15 \%$, the creep of concrete at a constant water-binder ratio of 0.35 was decreased by $20 \% \sim 30 \%$. Brooks et al. ${ }^{(17)}$ presented an experimental investigation on the effect of partial replacements of Portland cement by MK on the creep of concrete at a constant water-binder ratio of 0.28 . Their results showed that, with the increase of MK content, the creep of concrete was decreased remarkably. When the MK content was up to $15 \%$, the creep of concrete was decreased by about $65 \%$. It was suggested that, if the concrete is required to have a low creep, MK could be considered as a supplementary cementitious material (SCM). Santos et al. ${ }^{(18)}$ investigated the effect of loading ages on the creep of concrete. It was found that after the concrete was loaded in one day, the creep of concrete with amount of $10 \% \mathrm{MK}$, $30 \%$ calcined clay, and $50 \%$ GGBS by the equivalent volume of binder was increased by $123 \%, 58 \%$, and $316 \%$, respectively. However, after the concrete was loaded in three days, the creep of concrete with the mineral admixtures was decreased significantly. When the loading age reached to seven days, the creep of concrete with $\mathrm{MK}$, calcined clay and GGBS was decreased by 59\%, 55\% and $77 \%$, respectively. The results also showed that GGBS has a great effect on the creep of mass concrete with different loaded ages. McCarthy et al. ${ }^{(19)}$ studied the effect of FA in a high amount of $45 \%$ by weight of binder on C50 concrete creep. It was reported that the creep of concrete with the addition of FA to rapid hardened cement was decreased by $50 \%$, compared to that of concrete prepared by ordinary Portland cement. Li et al. ${ }^{(20)}$ reported that the addition of GGBS in amount of $30 \%$ by weight of binder could decrease the concrete creep by $50 \%$. The combined use of GGBS in amount of $30 \%$ and silica fume in amount of $10 \%$ by weight of binder could decrease the concrete creep by $65 \%$.

The above literature survey shows that there are numerous studies on the effect of individual mineral admixtures on concrete creep, which demonstrated that the mineral admixtures added to concrete can remarkably change the properties and performance of the concrete including creep through their physical and chemical effects. ${ }^{(21,22)}$ However, there is lack of systematical comparisons of creep between concretes with different mineral admixtures. More importantly, when the effect of mineral admixtures on concrete creep was studied previously, the replacement percentages of cement by mineral admixtures were often changed. Therefore, the effect of different mineral admixtures on concrete creep can not be compared effectively. In this paper an experimental investigation is presented on the mechanical properties and creep behaviour of concretes with added mineral admixtures with a fixed replacement percentage of cement. The influences of the different mineral admixtures on the mechanical properties, creep and pore microstructure organization of the mixed concrete are to be examined and compared.

\section{EXPERIMENTAL DETAILS}

\subsection{Materials}

The cement used in the experiments was Portland cement (PC) of grade P. I52.5 according to Chinese National Standard GB 175-2007 Common Portland Cement, whose specific surface area was $370 \mathrm{~m}^{2} / \mathrm{kg}$. Class I FA was used according to Chinese National Standard GB/T1596-2005 Fly Ash Used for Cement and Concrete, whose specific surface area was $550 \mathrm{~m}^{2} / \mathrm{kg}$. Class S95 GGBS was selected according to Chinese National Standard GB/T 18046-2008 Ground Granulated Blast Furnace Slag Used for Cement and Concrete, whose specific surface area was $420 \mathrm{~m}^{2} / \mathrm{kg}$. MK was obtained by the calcinations of kaolinitic clay at $800{ }^{\circ} \mathrm{C}$ for 4 hours, whose specific surface area was $1200 \mathrm{~m}^{2} / \mathrm{kg}$. Table I shows the chemical compositions of the PC, FA, GGBS and MK used in the experiments.

The inert mineral admixtures were also used in the experiments, including limestone powder (LP), quartz sand powder (QSP) and emery powder (EP), whose purities

Table I. Chemical compositions of PC, FA, GGBS and MK (wt \%).

\begin{tabular}{lccccccccc}
\hline Materials & $\mathrm{SO}_{3}$ & $\mathrm{SiO}_{2}$ & $\mathrm{Fe}_{2} \mathrm{O}_{3}$ & $\mathrm{Al}_{2} \mathrm{O}_{3}$ & $\mathrm{CaO}$ & $\mathrm{MgO}$ & $\mathrm{K}_{2} \mathrm{O}$ & $\mathrm{Na}_{2} \mathrm{O}$ & $\mathrm{TiO}_{2}$ \\
\hline PC & 2.54 & 21.10 & 3.26 & 4.77 & 62.63 & 1.15 & 0.43 & 0.05 & 0.28 \\
FA & 0.51 & 51.81 & 6.38 & 27.29 & 7.62 & 1.33 & 1.26 & 0.65 & 1.12 \\
GGBS & 0.24 & 33.63 & 0.46 & 15.64 & 38.34 & 8.58 & 0.46 & 0.22 & 0.68 \\
MK & 0 & 54.25 & 0.76 & 42.72 & 0.36 & 0 & 0.34 & 0 & 0.27 \\
\hline
\end{tabular}



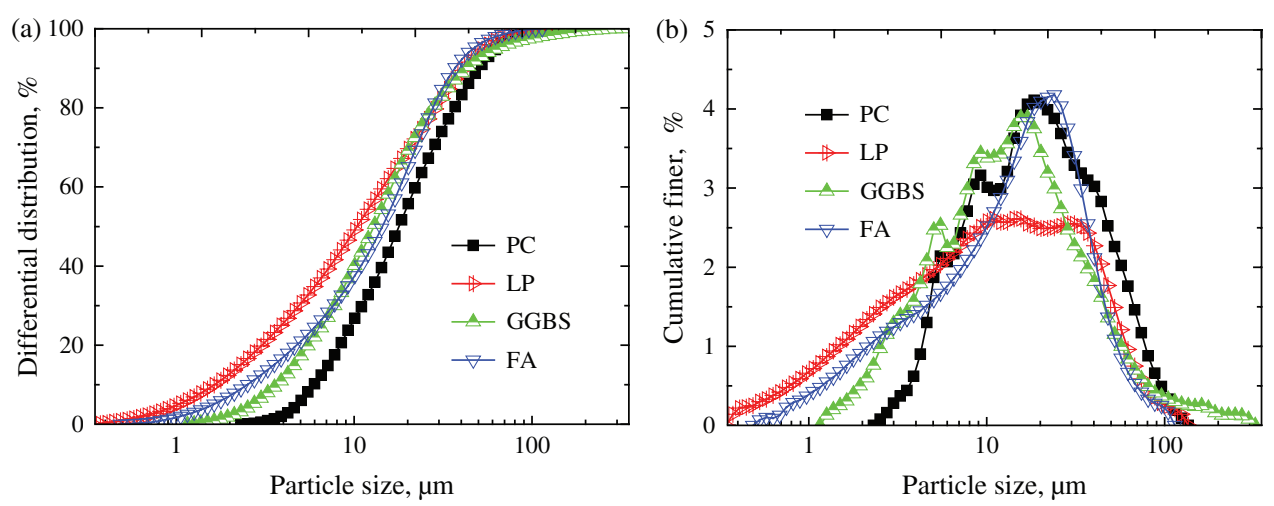

Fig. 1. Grading curves and particle size distributions of Portland cement (PC), limestone powder (LP), ground granulated blast-furnace slag (GGBS) and fly ash (FA) (a) grading curves and (b) Particle size distributions.

were higher than $90 \%$ and specific surface areas were $550 \mathrm{~m}^{2} / \mathrm{kg}, 750 \mathrm{~m}^{2} / \mathrm{kg}$ and $880 \mathrm{~m}^{2} / \mathrm{kg}$, respectively. The grading curves and particle size distributions of PC, LP, GGBS and FA were determined by laser particle analysis using BT-9300 Laser Particle Analyzer, which are shown in Figure 1. It can be seen from the figure that the average particle size of FA, GGBS or LP is smaller than that of PC particles. When PC is replaced by FA, GGBS and/or LP, the mineral admixtures can be considered as micro fillers in the concrete.

The scanning electron microscope (SEM) images of MK, LP, QSP, and EP are shown in Figure 2, which are obtained by S-4800 field emission scanning electron microscope made in Japan. The accelerating voltage of the instrument is $20 \mathrm{kV}$. It can be seen from the figure that the shape of MK is like a plate, which has a rough surface. As for inert mineral admixtures, QSP has a rough surface also, and however, LP and EP have the angular surfaces. LP and

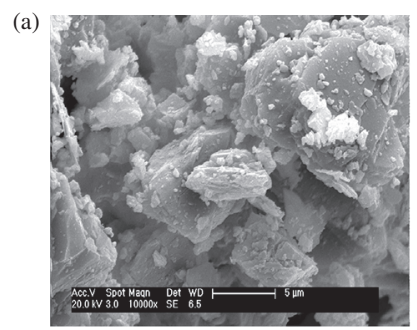

(c)
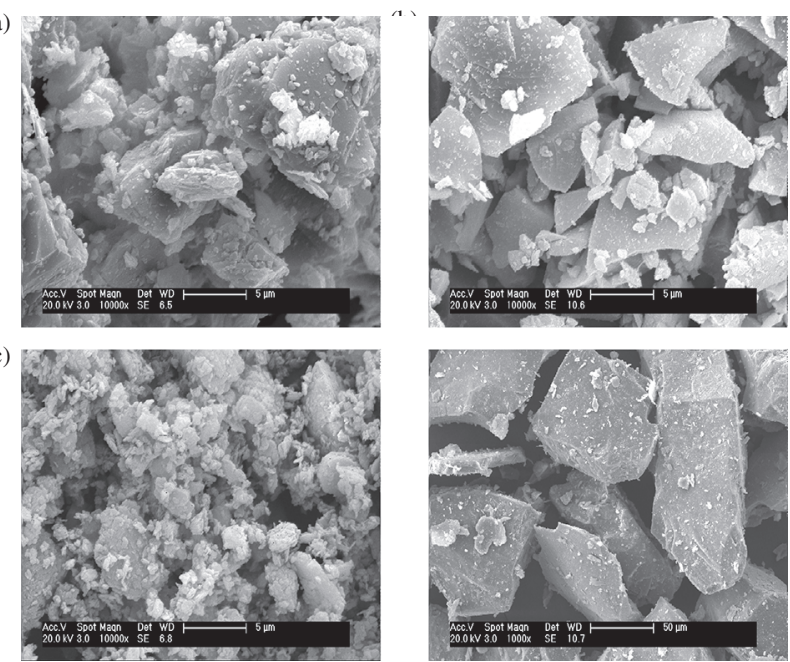

Fig. 2. Scanning electron microscope (SEM) images of some mineral admixtures (a) metakaolin (MK), (b) limestone powder (LP), (c) quartz sand powder (QSP) and (d) emery powder (EP).
EP do not improve the liquidities of concrete according to their shapes, but are helpful to enhance the strength of concrete by providing the interlock effect.

River sand was used for fine aggregates, which has a fineness modulus of 2.5 and grading II as regulated by Chinese National Standard JGJ52-2006 Standard for Technical Requirements and Test Method of Sand and Stone (or Gravel) for Ordinary Concrete. Crushed limestone with a size range from $5.0 \mathrm{~mm}$ to $25 \mathrm{~mm}$ was used as coarse aggregates. In addition, the polycarboxylic superplasticizer admixture with water reducing ratio $25 \%$ and local fresh clean tap water were used in the experiments.

\subsection{The Concrete Mixture Proportioning}

Seven mixtures were designed to investigate the creep of concrete with different mineral admixtures, in which the sand percentage (40\%), water-binder ratio $(0.3)$ and cementitious material amount $\left(480 \mathrm{~kg} / \mathrm{m}^{3}\right)$ were all kept as constants, and the slump of $200-220 \mathrm{~mm}$ was maintained by adjusting the superplasticizer content. Table II shows the details of the components used in the mixtures. The mix without mineral admixture was viewed as the control mix (C), and the other six mixes were designed on the basis of different mineral admixtures, with a constant percentage of mineral admixtures replacement $30 \%$ by weight. For example, 7C + 2FA + GGBS means that $70 \%$ of the binder weight is PC, $20 \%$ and $10 \%$ of the binder weight are FA and GGBS, respectively. In addition, different mineral admixtures used to replace PC were divided into two groups. Since FA and GGBS are the traditional mineral admixtures, they are as the reference group in this study. MK is a relatively new mineral admixture, which has high pozzolanic activity than that of FA and GGBS. Usually, the concrete with MK has high strength. However, because MK is very expensive, it is not feasible to use MK alone in the concrete. For this reason, other mineral admixtures such as LP, QSP and EP are used with MK in the present study. 
Table II. Mix proportions of concrete with different mineral admixtures $\left(\mathrm{kg} / \mathrm{m}^{3}\right)$.

\begin{tabular}{|c|c|c|c|c|c|c|c|}
\hline \multirow{2}{*}{$\frac{\text { Types of mixture }}{\text { C }}$} & \multirow{2}{*}{$\frac{\mathrm{PC}}{480}$} & \multicolumn{2}{|c|}{ Mineral admixture } & \multirow{2}{*}{$\frac{\text { Sand }}{708}$} & \multirow{2}{*}{$\begin{array}{c}\text { Gravel } \\
1062\end{array}$} & \multirow{2}{*}{$\frac{\text { Water }}{144}$} & \multirow{2}{*}{$\frac{\text { Superplasticizer }}{2.88}$} \\
\hline & & 0 & 0 & & & & \\
\hline $7 \mathrm{C}+3 \mathrm{FA}$ & 336 & 144 (FA) & 0 & 708 & 1062 & 144 & 2.40 \\
\hline $7 \mathrm{C}+3 \mathrm{GGBS}$ & 336 & 144 (GGBS) & 0 & 708 & 1062 & 144 & 2.70 \\
\hline $7 \mathrm{C}+2 \mathrm{FA}+\mathrm{GGBS}$ & 336 & $96(\mathrm{FA})$ & 48 (GGBS) & 708 & 1062 & 144 & 2.64 \\
\hline $7 \mathrm{C}+\mathrm{MK}+2 \mathrm{LP}$ & 336 & 48 (MK) & 96 (LP) & 708 & 1062 & 144 & 2.88 \\
\hline $7 \mathrm{C}+\mathrm{MK}+2 \mathrm{QSP}$ & 336 & $48(\mathrm{MK})$ & 96 (QSP) & 708 & 1062 & 144 & 2.88 \\
\hline $7 \mathrm{C}+\mathrm{MK}+2 \mathrm{EP}$ & 336 & 48 (MK) & $96(\mathrm{EP})$ & 708 & 1062 & 144 & 2.88 \\
\hline
\end{tabular}

\subsection{Test Methods}

Apart from the creep data, the compressive strength, elastic modulus, drying shrinkage, internal relative humidity (IRH), and pore size distribution of the concrete mixes are also tested. The dimensions of specimens used for the compressive strength and elastic modulus tests were $150 \mathrm{~mm} \times 150 \mathrm{~mm} \times 150 \mathrm{~mm}$ and $150 \mathrm{~mm} \times 150 \mathrm{~mm} \times$ $300 \mathrm{~mm}$, respectively. The tests were conducted at the ages of 7,28, 60 and 90 days, respectively. After mixing and casting, the specimens were kept in moulds for about 24 hours at room temperature $(20 \pm 5){ }^{\circ} \mathrm{C}$. Afterwards, they were demoulded and placed in a standard curing room of controlled temperature $(20 \pm 2){ }^{\circ} \mathrm{C}$ and relative humidity more than $95 \%$ until they were tested.

For the creep and IRH tests, a self-made testing device is used, which is shown in Figure 3. During the test four specimens, each has the dimensions of $130 \times 130 \times$ $400 \mathrm{~mm}^{3}$ and a $30 \mathrm{~mm}$ diameter hole in the middle, were connected by a steel bar. Steel clapboards were placed between the specimens and on the loading surfaces where a pressure sense was also positioned. The steel bar has a

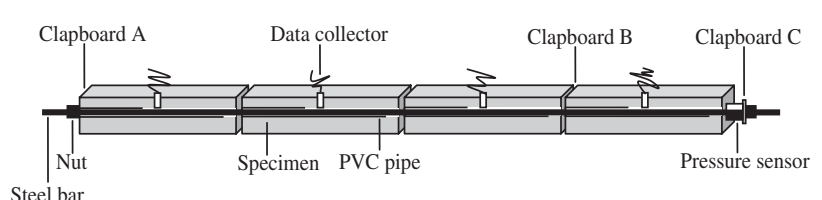

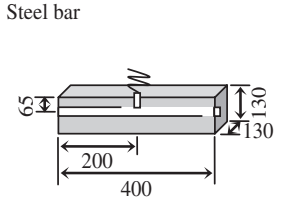

(b) Specimendimension

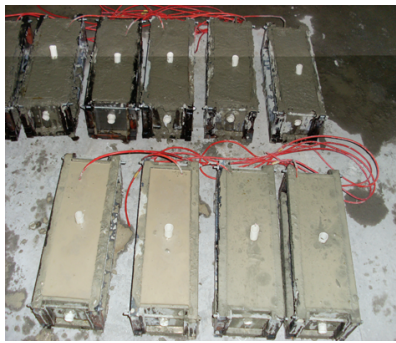

(f) Preparation process (a) Test diagram

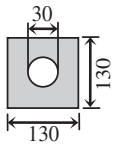

(c) Clapboard A $(130 \times 130 \times 20)$

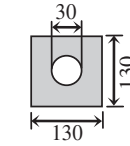

(d) ClapboardB $(130 \times 130 \times 10)$

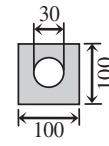

(e) ClapboardC $(100 \times 100 \times 20)$

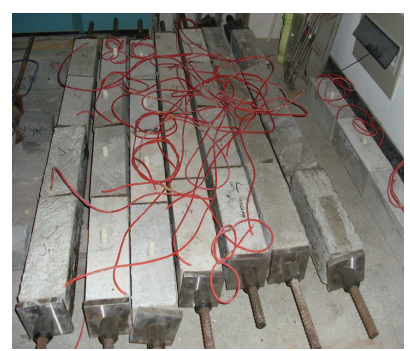

(g) Test process
Fig. 3. Internal relative humidity and creep tests of specimens (Unit: millimeter) diameter of $25 \mathrm{~mm}$ and it was inserted into a PVC pipe with outer and inner diameters of $30 \mathrm{~mm}$ and $25 \mathrm{~mm}$. The loading on the specimens was controlled by the steel bar and the data were recorded during the period of the test. In addition, a digital humidity sensor and a vibration string type strain gauge were embedded at the centre of the tested specimen for recording the axial compressive strain and IRH of the specimen. During the test the temperature and the relative humidity were controlled at $(20 \pm 2)^{\circ} \mathrm{C}$ and $(60 \pm 5) \%$, respectively.

The loading stress of the self-made testing device may show the relaxation phenomenon during a long term loading. If the loading stress calculated by the pressure sensor is less than $2 \%$ of the initial loading stress, the prestress of the specimen should be added immediately to ensure the long term loading stress remain a constant.

The compressive stress applied to the specimens was controlled to about $28 \%$ of the corresponding cubic compressive strength at 7 days, which was controlled using the vibration string type pressure sensor. In addition, in order to eliminate drying shrinkage, the shrinkage strain of the specimen with the same dimensions but without loading was tested at the same time. Creep strain was calculated by subtracting drying shrinkage strain of the non-loaded specimen from the total longitudinal strain of the loaded specimen. Specific creep is used to analyze the creep data obtained from the tests, which can be calculated as follows: ${ }^{(23)}$

$$
C_{t}=\left(\varepsilon_{c t}-\varepsilon_{t}\right) / \sigma=3.57\left(\varepsilon_{c t}-\varepsilon_{t}\right) / f_{c}
$$

where $C_{t}$ is the specific creep at the loading age of $t$ days, $\varepsilon_{c t}$ is the creep strain at the loading age of $t$ days, $\varepsilon_{t}$ is the drying shrinkage strain of concrete at the same loading age as the creep strain, $\sigma=0.28 f_{c}$ is the applied compressive stress, and $f_{c}$ is the cubic compressive strength of the concrete mix used to cast the specimen at 7 days.

In order to examine the effect of pore microstructure of the hardened concrete specimens with different mineral admixtures on the creep, mercury intrusion porosimetry (MIP) was used to measure the pore size distribution of the concrete mixes at 28 days. The MIP used is able to generate pressures up to $420 \mathrm{MPa}$ and measure pores of diameters ranging from $3.5 \mathrm{~nm}$ to $400 \mu \mathrm{m}$. The specimens used for the MIP test were broken into small pieces of size 
3-5 mm, which consist of only mortar and fine aggregates, and stored in ethanol solution for three days to prevent further hydration and/or carbonation. After then, they were dried and stored in sealed containers before the MIP test was carried out.

\section{RESULTS AND DISCUSSION}

\subsection{Compressive Strength and Elastic Modulus}

Figure 4 shows the variation of the compressive strengths of the specimens tested at different ages. Each point represents the average value of three tested specimens with identical mixtures.

It can be seen from Figure 4(a) that, for specimens with FA and/or GGBS, their early compressive strengths are lower than that of the control specimen. It is only after about 60 days, the compressive strength is higher in the specimen with GGBS or with both FA and GGBS, but remains lower in the specimen with FA alone. In contrast, most of the compressive strengths of the specimens with MK and inert mineral admixture systems tested within 90 days are lower than that of the control specimen (see Fig. 4(b)). It is only the specimens $(7 \mathrm{C}+\mathrm{MK}+2 \mathrm{EP})$ and $(7 \mathrm{C}+\mathrm{MK}+2 \mathrm{QSP})$ that at 90 days have the comparable compressive strengths to the control specimen. The different effects of EP, QSP and LP on the compressive strength of the mixed concrete could be attributed to the comprehensive results of their particle sizes, shapes and hardness.

Figure 5 shows the variation of the elastic modulus of the specimens at different ages. Similar to the compressive strength, each data point represents the average value of three tested specimens with identical mixtures.

It can be observed from the figure that, except for the specimen with both FA and GGBS that has a slightly greater elastic modulus at 90 days than the control specimen, all other specimens have lower elastic modulus than the control specimen. For the specimens with MK and inert mineral admixture systems it seems that the combination of MK and LP has almost no influence on the elastic modulus after 28 days, whereas the combination of MK and EP or MK and QSP can increase the elastic modulus. In terms of the value of elastic modulus, the order can be approximated as $(7 \mathrm{C}+\mathrm{MK}+2 \mathrm{EP})>(7 \mathrm{C}+\mathrm{MK}+2 \mathrm{QSP})>\mathrm{C}>1$ or $\sim(7 \mathrm{C}+\mathrm{MK}+2 \mathrm{LP})$.

\subsection{Creep}

The specific creep of the specimens with different mineral admixtures at different times are calculated using Eq. (1) based on the creep strain, drying shrinkage strain and applied stress obtained in the test. Figure 6 shows the variation of the specific creep with time for each specimen. It can be seen from the figure that the specific creep for all these specimens has a general trend, that is, it increases quickly with time during the first 40 days, then becomes stabilized and turns to be constant.

It can be seen from Figure 6(a) that the addition of FA and/or GGBS can reduce the specific creep of the mixed concrete. For the same amount of FA, GGBS and FA+ GGBS, the combined use of FA and GGBS results in the lowest specific creep, while the addition of FA alone is slightly better than the addition of GGBS alone in terms of the reduction of the specific creep. Compared to the control specimen, the stabilized specific creep of the specimens with (FA + GGBS), FA and GGBS has reduced by $31 \%, 12 \%$ and $5 \%$, respectively.

When the use of MK is combined with LP, QSP or EP, the specific creep of the mixed concrete can be significantly reduced. As it can be seen from Figure 6(b) that, the stabilized specific creep of the specimens with $(\mathrm{MK}+$ $2 \mathrm{EP}),(\mathrm{MK}+2 \mathrm{QSP})$ and (MK + 2LP) has reduced by $46 \%$, $39 \%$ and $30 \%$, respectively, when it is compared to that of the control specimen. The reason for this is likely due to the MK, which has high pozzolanic activity, and the inert mineral admixtures, which have high elastic modulus.

Pourbeik et al. ${ }^{(24)}$ reported that creep of both the old paste (45 years) and young paste (2 months) at $11 \%$ relative humidity or less was dependent on the water content. Interlayer water appeared to have a structural role in the creep process. Wyrzykowski et al. ${ }^{(25)}$ investigated the effect of external load on IRH in concrete. An instantaneous IRH increase of almost $2 \%$ IRH inside sealed mortar
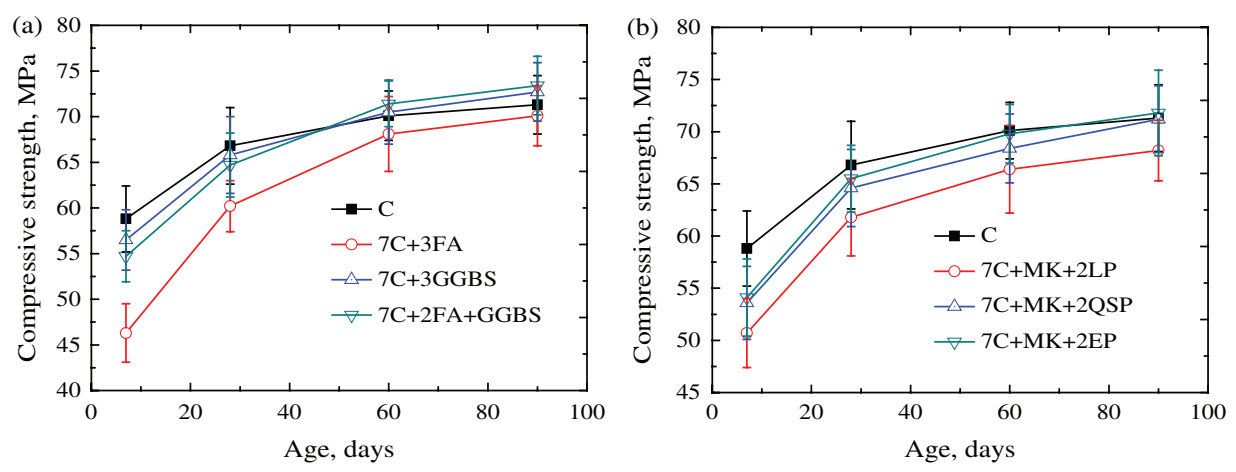

Fig. 4. Effect of mineral admixtures on the compressive strengths of concrete (a) fly ash (FA) and ground granulated blast-furnace slag (GGBS) and (b) metakaolin (MK) and inert mineral admixtures. 

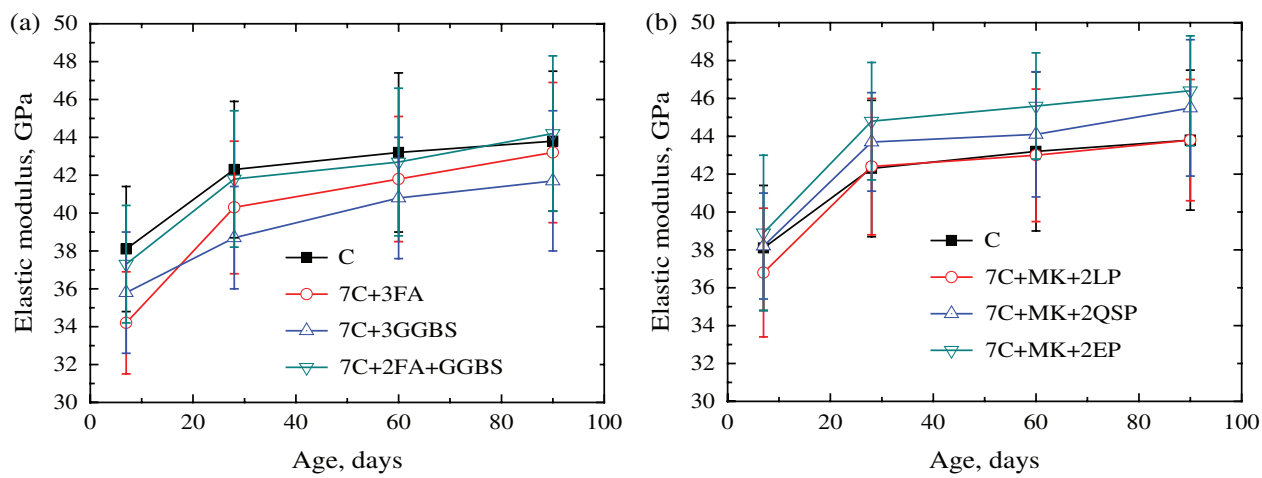

Fig. 5. Effect of mineral admixtures on the elastic modulus of concrete (a) fly ash (FA) and ground granulated blast-furnace slag (GGBS) and (b) metakaolin (MK) and inert mineral admixtures.

specimens at loading with a stress/strength ratio of $30 \%$ was found. The initial IRH increase was further recovered over time while the specimen was under a constant load. Upon unloading, an instantaneous IRH decrease of roughly the same magnitude took place. The observed results supported the theory of local water redistribution from loadbearing water layers in hindered adsorption areas toward larger pores as a result of applied compressive stress, which was relevant for understanding concrete creep.

It is generally recognized that creep is closely related to the water chemically bound to the cement paste and its release from the solid phase into liquid phase, which can be represented by the IRH inside of the concrete. Figure 7 shows the variation of IRH with time in the specimens with the FA or the MK and inert mineral admixture systems. For each specimen there two curves shown in the figure; one is for the specimen with an applied compressive stress $(28 \%$ of the corresponding cubic compressive strength) and the other is for the specimen without the applied stress.

It can be seen from Figure 7 that, for all specimens the IRH decreases with time although the rate of decrease is different for different specimens. Also it can be observed from the figure that the applied stress seems to have no remarkable effect on the IRH. It is noticed that for all specimens the decrease of IRH occurs mainly in the first 100 days. After the 100 days the IRH is almost stabilized. In terms of the IRH value, the specimens have the order of $(7 \mathrm{C}+\mathrm{MK}+2 \mathrm{EP})>(7 \mathrm{C}+\mathrm{MK}+2 \mathrm{QSP})>(7 \mathrm{C}+\mathrm{MK}+$ $2 \mathrm{LP})>(7 \mathrm{C}+3 \mathrm{FA})$. This order is closely correlated to the specific creep order of the specimens shown in Figure 6.

To identify the correlation between the IRH and specific creep, Figure 8 plots the relationship between the IRH and specific creep of the specimens obtained from the test.

It can be seen from the figure that, for each specimen the variation of its specific creep with IRH can be characterized by three different zones. The first zone is for very low IRH where the specific creep is stabilized and thus has almost no change with IRH. This zone mainly occurs after a certain ages. The second zone is for very high IRH where the specific creep decreases rapidly with the increased IRH. This zone occurs mainly in the first few days. The third zone is the majority part (i.e., except for the two end zones) of IRH where the decrease of the specific creep is almost linearly proportional to the increase of IRH; i.e., there is a linear relationship between the specific creep and the IRH.

Note that for the same IRH the specific creeps are different in different specimens. For example, the stabilized specific creeps are about $23 \times 10^{-6} / \mathrm{MPa}, 18.5 \times 10^{-6} / \mathrm{MPa}$,
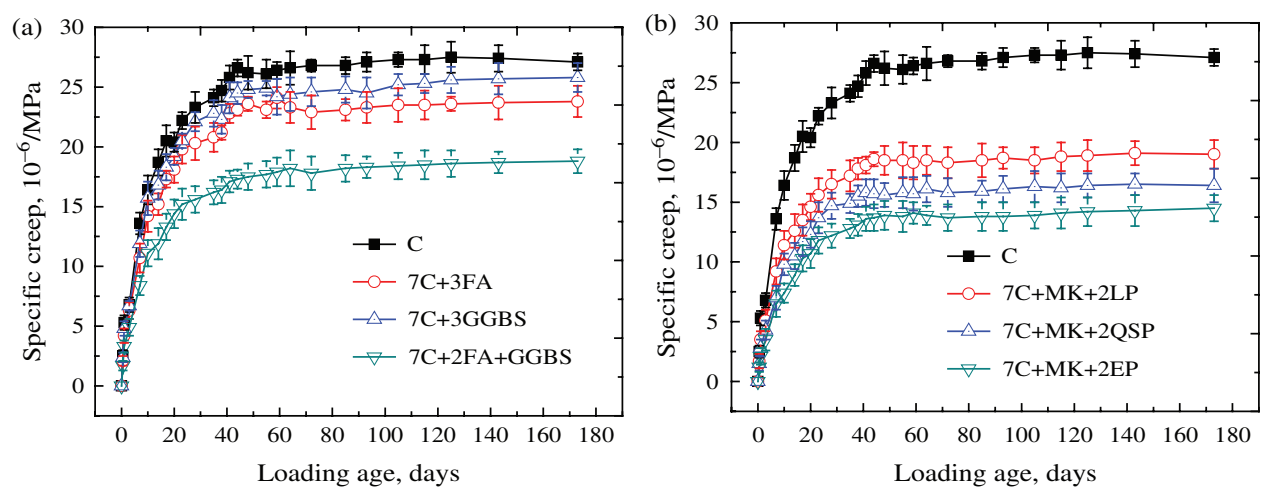

Fig. 6. Effect of mineral admixtures on creep of concrete (a) fly ash (FA) and ground granulated blast-furnace slag (GGBS) and (b) metakaolin (MK) and inert mineral admixtures. 


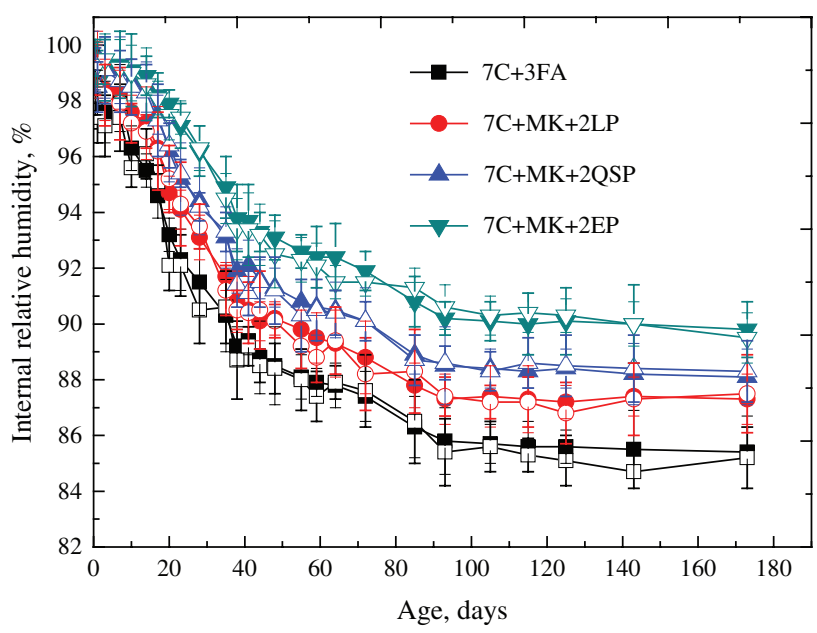

Fig. 7. Effect of fly ash (FA) or the metakaolin (MK) and inert mineral admixtures on internal relative humidity (IRH) of concrete (solid symbols are with applied stress and hollow symbols are without applied stress).

$16 \times 10^{-6} / \mathrm{MPa}$ and $14 \times 10^{-6} / \mathrm{MPa}$ for the specimens of $(7 \mathrm{C}+3 \mathrm{FA}),(7 \mathrm{C}+\mathrm{MK}+2 \mathrm{LP}),(7 \mathrm{C}+\mathrm{MK}+2 \mathrm{QSP})$, and $(7 \mathrm{C}+\mathrm{MK}+2 \mathrm{EP})$, respectively. The reason for this is likely due to the difference in porosity and pore size distribution in mixed concretes owing to the use of different SCMs.

\subsection{Pore Micro-Structure}

The mechanical properties of concrete depend largely on the pore microstructure of the concrete. The addition of SCMs in concrete will influence its pore microstructure. Figure 9 shows the pore-size distributions of specimens with different mixtures, which were measured using MIP at 28 day ages.

It can be seen from Figure 9(a) that, the addition of FA in concrete results in a reduction of pore volume of pore size larger than $30 \mathrm{~nm}$, whereas the addition of GGBS in

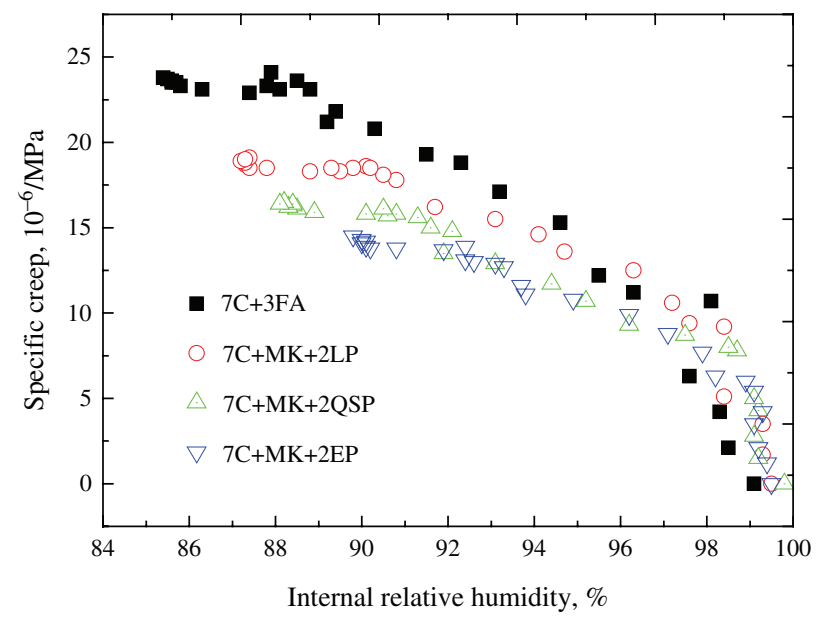

Fig. 8. Relationships between specific creep and internal relative humidity (IRH). concrete results in a reduction of pore volume of pore size smaller than $100 \mathrm{~nm}$. The combined use of FA and GGBS seems able to reduce the pore volume of pores of different ranges.

Compared to the concrete mixes with FA and/or GGBS, the concrete mixes with MK and inert mineral admixtures have very similar pore size distribution, indicating that EP, QSP, and LP have almost the same effect on pore size distribution. It can be observed from Figure 9(b) that, the smaller the pore size is, the more reduction the pore volume has. Overall, the concrete mixes with MK and inert mineral admixtures have lower pore volumes, particularly, to the pores of small size.

\subsection{Discussion}

Note that the creep of concrete can be affected by many factors, such as curing system, testing method, type and amount of aggregate, properties and amount of hardened cement paste. ${ }^{(20,26)}$ In this study, only the factor, which is the type of mineral admixtures with a fixed replacement percentage of cement, is investigated. The variation of mineral admixtures of binders leads to the different properties of hardened cement paste, which thus also affects the variation of creep of concrete. In addition, there is a direct relationship between the specific creep and the applied compressive stress according to Eq. (1). Extensive researches ${ }^{(27-29)}$ have proved that the creep of concrete increases with the increase of the applied stress generally. In the present study, the applied compressive stress of concrete is about $28 \%$ of the corresponding cubic compressive strength at 7 days in the process of concrete creep tests (i.e., $\sigma=0.28 f_{c}$ ). The compressive strength of the control concrete is higher than those of all concrete with different mineral admixtures at 7 days due to their slow pozzolanic reactions. With the increase of ages, the compressive strengths of concrete with different mineral admixtures increase obviously after 7 days, and the strength gaps between the control concrete and concrete with different mineral admixtures are smaller and smaller according to Figure 4. Especially, the concrete with GGBS or with both FA and GGBS have the higher compressive strength than that of the control concrete after 60 days, and the concrete with MK and EP or QSP have the comparable compressive strengths to the control concrete at 90 days. Therefore, it can be deduced that the effective compressive stress applied in creep tests of concrete with different mineral admixtures is smaller and smaller. This is due to the fact that the increase rates of strengths of concrete with different mineral admixtures are higher than that of the control concrete. Therefore, the different mineral admixture can decrease effectively the creep of concrete. McCarthy et al. ${ }^{(19)}$ also reported that the creep of concrete with the addition of FA to rapid hardened cement was decreased by $50 \%$, compared to that of concrete prepared by ordinary Portland cement. However, the creep of concrete with FA has only decreased by $12 \%$. This difference 

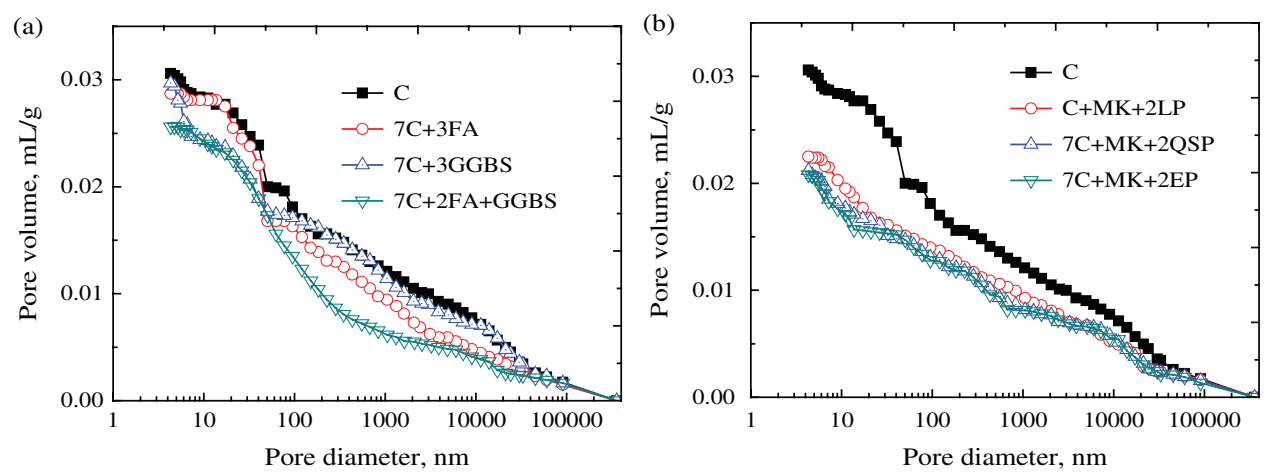

Fig. 9. Effect of mineral admixtures on cumulative porosity of specimens (a) fly ash (FA) and ground granulated blast-furnace slag (GGBS) and (b) metakaolin (MK) and inert mineral admixtures.

of the decrease rates can be explained by the used cement. The rapid hardened cement can increase the strengths of concrete with FA more quickly than the ordinary Portland cement, to decrease the effective compressive stress more remarkably.

The elastic modulus of concrete is one of the important mechanical properties, which is related with the creep of concrete directly. The concrete with FA and/or GGBS have lower elastic modulus than the control concrete except for the concrete with both FA and GGBS at 90 days. The concrete with both MK and QSP or EP have greater elastic modulus than that of the control concrete. The combination of MK and LP has almost no influence on the elastic modulus after 28 days. The variations of elastic modulus of concrete are due to the different pozzolanic reactions as well as the elastic modulus of mineral admixtures themselves. ${ }^{(30,31)}$ MK has a higher activity than FA and GGBS, which makes concrete stronger and more resistant to creep. The elastic modulus of cement used in this study is greater than those of FA and GGBS, but lower than those of LP, QSP and EP. ${ }^{(32)}$ The unhydrated active mineral admixtures and inert mineral admixtures act as fine aggregate to provide the different resistance against creep according to their elastic modulus. The comparison of Figures 5 and 6 shows that the greater elastic modulus of concrete corresponds to the lower creep mainly. However, creep of concrete is also affected by the strengths of concrete which are related with the effective compressive stress. For example, FA and/or GGBS decrease not only the elastic modulus of concrete but also the creep of concrete.

In general, mineral admixtures can improve the pore structure of hardened cement paste to affect the variation of creep of concrete. ${ }^{(33)} \mathrm{MK}$ is a highly active material, which reacts with calcium hydroxide originated from cement hydration to produce additional $\mathrm{C}-\mathrm{S}-\mathrm{H}$. The additional $\mathrm{C}-\mathrm{S}-\mathrm{H}$ fills some of concrete pores or voids and thus reduces the porosity of the mixes. In contrast, the pozzolanic activity of GGBS, and particularly FA is rather low. This is why the reduction in porosity by adding them into concrete is limited. This is consistent with the results of concrete with modified admixtures by studying the relationships between IRH and creep from our published literature. ${ }^{(34)}$ In addition, mineral admixtures can also fill the small pores and voids which are harmful to structure and properties of concrete. Therefore, the comparison of Figures 9 and 6 shows that there is an association between the pore size distribution and specific creep of the concrete. In general, the smaller the porosity, the lower the creep, indicating that a more dense concrete could provide more resistance to its creep. Note that the result of Li et al. ${ }^{(20)}$ showed that GGBS could reduce the concrete creep by $50 \%$; while the present experimental data showed it reduces the concrete creep only by $5 \%$. This big difference is likely due to the use of different types of GGBS. In Li et al. work the GGBS used has a specific surface area of $800 \mathrm{~m}^{2} / \mathrm{kg}$; while in our tests the GGBS has a specific surface area of only $420 \mathrm{~m}^{2} / \mathrm{kg}$.

\section{CONCLUSION}

The mechanical properties and creep of concrete specimens with different mineral admixtures were evaluated experimentally in this study. In addition, the pore-size distribution of the mixed concrete was also measured using MIP technique and its correlation with creep was discussed. Based on the present study, the following conclusions can be drawn:

- The addition of GGBS or together with FA results in a decrease of early compressive strength of the specimen, but this decrease will be overtaken by the strength increase in the late stage. The addition of MK and inert mineral admixtures also decreases the compressive strength of mixed concrete, and the reduction range depends mainly on the particle sizes of the inert mineral admixtures.

- The additions of FA or/and GGBS decrease the early elastic modulus of the specimens. However, the addition of MK and QSP or EP can increase the elastic modulus of the mixed concrete. The addition of MK and LP has little effect on the elastic modulus of the mixed concrete. 
- The use of FA and/or GGBS can reduce the creep of concrete, particularly the stabilized specific creep. However, more creep can be reduced if the mineral admixtures are used in concrete owing to the high pozzolanic activity of MK and the high elastic modulus of inert mineral admixtures.

- The correlation between specific creep and IRH can be characterized in three different zones. If a linear relationship is used between the specific creep and IRH then one should use different slops for different zones.

- The addition of FA and GGBS in concrete can reduce the large and small pores of the concrete, respectively. Thus, the combined use of FA and GGBS can reduce the pore volume of pores of different sizes. Compared to the concrete mixes with FA and/or GGBS, the concrete mixes with MK and inert mineral admixtures have very similar pore size distribution.

Acknowledgments: The authors would like to acknowledge the National Natural Science Foundation of China (Grant No. 41427802) and the Shaoxing University Scientific Research Project (Grant No. 20145030) for their financial support to the work presented in this paper.

\section{References and Notes}

1. F. Benboudjema, F. Meftah, and J. M. Torrenti; Interaction between drying, shrinkage, creep and cracking phenomena in concrete; Eng. Struct. 27, 239 (2005).

2. P. Rossi, J. L. Tailhan, F. L. Maou, L. Gaillet, and E. Martin; Basic creep behavior of concretes investigation of the physical mechanisms by using acoustic emission; Cem. Concr. Res. 42, 61 (2012).

3. J. J. Brooks; 30-year creep and shrinkage of concrete; Mag. Concr. Res. 57, 545 (2005).

4. Z. P. Bazant and G. H. Li; Comprehensive database on concrete creep and shrinkage; ACI Mater. J. 105, 635 (2008).

5. P. Meshgin, K. K. Choi, and M. M. R. Taha; Experimental and analytical investigations of creep of epoxy adhesive at the concreteFRP interfaces; Int. J. Adhes. Adhes. 29, 56 (2009).

6. F. T. K. Au and X. T. Si; Accurate time-dependent analysis of concrete bridges considering concrete creep, concrete shrinkage and cable relaxation; Eng. Struct. 33, 118 (2011).

7. I. N. Robertson; Prediction of vertical deflections for a long-span prestressed concrete bridge structure; Eng. Struct. 27, 1820 (2005).

8. M. Vandamme and F. J. Ulm; Nanogranular origin of concrete creep; P. Natl. Acad. Sci. USA 106, 10552 (2009).

9. L. Sorelli, G. Constantinides, F. J. Ulm, and F. Toutlemonde; The nano-mechanical signature of ultra high performance concrete by statistical nanoindentation techniques; Cem. Concr. Res. 38, 1447 (2008).

10. C. A. Jones and Z. C. Grasley; Short-term creep of cement paste during nanoindentation; Cem. Concr. Compos. 33, 12 (2011).

11. R. Siddique and J. Klaus; Influence of metakaolin on the properties of mortar and concrete: A review; Appl. Clay. Sci. 43, 392 (2009).

12. R. S. Iyer and J. A. Scott; Power station fly ash-a review of valueadded utilization outside of the construction industry; Resour. Conserv. Recy. 31, 217 (2001).
13. C. J. Shi and J. S. Qian; High performance cementing materials from industrial slags-a review; Resour. Conserv. Recy. 29, 195 (2000).

14. R. P. Khatri, V. Sirivivatnanon, and W. Gross; Effect of different supplementary cementitious materials on mechanical properties of high performance concrete; Cem. Concr. Res. 25, 209 (1995).

15. R. Siddique; Utilization of silica fume in concrete: Review of hardened properties; Resour. Conserv. Recy. 55, 923 (2011).

16. M. Mazloom, A. A. Ramezanianpour, and J. J. Brooks; Effect of silica fume on mechanical properties of high-strength concrete; Cem. Concr. Compos. 26, 347 (2004).

17. J. J. Brooks and M. A. M. Johari; Effect of metakaolin on creep and shrinkage of concrete; Cem. Concr. Compos. 23, 495 (2001).

18. S. B. dos Santos, L. C. P da Silva Filho, and J. L. Calmon; Early-age creep of mass concrete: Effects of chemical and mineral admixtures; ACI Mater. J. 109, 537 (2012).

19. M. J. McCarthy and R. K. Dhir; Development of high volume fly ash cements for use in concrete construction; Fuel. 84, 1423 (2005).

20. J. Y. Li and Y. Yao; A study on creep and drying shrinkage of high performance concrete; Cem. Concr. Res. 31, 1203 (2001).

21. J. W. Bullard, H. M. Jennings, R. A. Livingston, A. Nonat, G. W. Scherer, J. S. Schweitzer, K. L. Scrivener, and J. J. Thomas; Mechanisms of cement hydration; Cem. Concr. Res. 41, 1208 (2011).

22. J. Stark; Recent advances in the field of cement hydration and microstructure analysis; Cem. Concr. Res. 41, 666 (2011).

23. Q. X. Zhao, X. C. Liu, and J. Y. Jiang; Effect of curing temperature on creep behavior of fly ash concrete; Constr. Build. Mater. 96, 326 (2015).

24. P. Pourbeik, J. J. Beaudoin, R. Alizadeh, and L. Raki; Creep of 45 year old cement paste: The role of structural water; Mater. Struct. 49, 739 (2016).

25. M. Wyrzykowski and P. Lura; The effect of external load on internal relative humidity in concrete; Cem. Concr. Res. 65, 58 (2014).

26. F. Lavergne, K. Sab, J. Sanahuja, M. Bornert, and C. Toulemonde; Investigation of the effect of aggregates' morphology on concrete creep properties by numerical simulations; Cem. Concr. Res. 71, 14 (2015).

27. C. Q. Lye, R. K. Dhir, G. S. Ghataora, and H. Li; Creep strain of recycled aggregate concrete; Constr. Build. Mater. 102, 244 (2016).

28. M. Shariq, J. Prasad, and H. Abbas; Creep and drying shrinkage of concrete containing GGBFS; Cem. Concr. Compos. 68, 35 (2016).

29. Q. X. Zhao, J. C. Yu, G. Q. Geng, J. Y. Jiang, and X. C. Liu; Effect of fiber types on creep behavior of concrete; Constr. Build. Mater. 105, 416 (2016).

30. K. Kuder, D. Lehman, J. Berman, G. Hannesson, and R. Shogren; Mechanical properties of self consolidating concrete blended with high volumes of fly ash and slag; Constr. Build. Mater. 34, 285 (2012).

31. J. H. Lee and Y. S. Yoon; The effects of cementitious materials on the mechanical and durability performance of high-strength concrete; KSCE J. Civil. Eng. 19, 1396 (2015).

32. Z. H. He, C. X. Qian, and F. Zhao; Experimental investigation of creep of cement paste with mineral admixtures via nanoindentation; Nanosci. Nanotech. Lett. 6, 51 (2014).

33. M. C. G. Juenger and R. Siddique; Recent advances in understanding the role of supplementary cementitious materials in concrete; Cem. Concr. Res. 78, 71 (2015).

34. Z. H. He and C. X. Qian; Internal relative humidity and creep of concrete with modified admixtures; Prog. Nat. Sci. Mater. Int. 21, 426 (2011). 